\title{
Social media as a tool for surgical education: a qualitative systematic review
}

\author{
Diego L. Lima ${ }^{1} \oplus$ - Valentina Viscarret ${ }^{1} \cdot$ Juan Velasco $^{1} \cdot$ Raquel Nogueira C. L. Lima $^{1} \cdot$ Flavio Malcher $^{2}$
}

Received: 8 December 2021 / Accepted: 15 February 2022 / Published online: 1 March 2022

(c) The Author(s), under exclusive licence to Springer Science+Business Media, LLC, part of Springer Nature 2022

\begin{abstract}
Background Social media use has exploded, attaining a significant influence within medicine. Previous studies have denoted the use of social media in various surgical specialties as a means to exchange professional ideas and improve the conference experience and at the same time, some have assessed its feasibility as a method of education. This systematic review aims to characterize the use of social media as a tool for general surgery education.

Methods A systematic review of several databases from each database inception was conducted following the PRISMA guidelines. The JBI's critical appraisal tools were used to assess quality of the studies.

Results A total of 861 articles were identified of which 222 were duplicates removed. The titles and abstracts from the remaining 639 abstracts were screened and 589 were excluded. The remaining 51 full articles were analyzed for eligibility, of which 24 met inclusion criteria and were included in the systematic review. These studies covered the general surgery specialty, of which $11(n=46 \%)$ focused on the laparoscopic surgical approach, $1(n=4 \%)$ on robotic-assisted surgical procedures, $1(n=4 \%)$ on both surgical approaches previously mentioned and $11(n=46 \%)$ on the general surgery specialty regardless of the surgical approach or technique.

Conclusions Advantages that SM offers should be considered, and content creators and institutions should help collectively to make sure that the content being published is evidence and guideline-based so its use it is taken to the maximum benefit.
\end{abstract}

Keywords Social media $\cdot$ Social networking $\cdot$ Education $\cdot$ Laparoscopy $\cdot$ Robotics $\cdot$ Minimally invasive surgery

The ways to communicate have changed and in the last two decades, social media use has exploded at the same time as internet access. The ability that it brings to interact with the society as well as to disseminate information and personal opinions has attained a significant influence within medicine [1]. This has impacted surgical education as nowadays it is possible to connect in real time with colleagues, students, residents, and attendings with the aim of sharing knowledge and improving patient outcomes [2].

Previous studies have reported on the adoption of social media across various surgical specialties. Urology experts have assessed the use of social media to amplify the conference experience to a wider audience [3], as well as an

Diego L. Lima

dilaurentino@gmail.com

1 Department of Surgery, Montefiore Medical Center, 1825 Eastchester Rd, Bronx, NY 10461, USA

2 Division of General Surgery, NYU Langone Health, New York, USA opportunity to exchange professional ideas across continents [4]. Authors have assessed the usefulness and the popularity of social media among plastic surgeons [5]; neurosurgery has evaluated the use of social media for case-based discussions as a method of education [6]. In our knowledge, there is no systematic review focused in general surgery field and the importance that has been given to social media in terms of education.

Therefore, the aim of this systematic review is to characterize the current use of social media as a tool for education in the general surgery field.

\section{Materials and methods}

This systematic review was registered in PROSPERO (the international prospective register of systematic reviews) with the registration number CRD42020153600. The PRISMA (Preferred Reporting Items for Systematic Reviews and Meta-Analyses) guidelines were followed at all stages of 
this systematic review [7]. We aim to present the results in a narrative form regarding the use of social media as a tool for general surgery education.

\section{Eligibility criteria}

The PECOS model (Population, Exposure, Comparison, Outcome, Study Design) was followed on the article screening to determine inclusion eligibility. A controlled vocabulary supplemented with keywords was used by the time of literature search. Observational studies included cohort and cross-sectional study designs. Descriptive studies were also included as well as randomized and non-randomized trials. Exclusion criteria included case reports, editorial letters to the editor, and general reviews; specialties other than general surgery; and manuscripts that were not in English, Portuguese, or Spanish. Participants selected were surgeons, residents, and medical students. No comparison group was used, and the intervention was exposed to social media.

\section{Information sources}

In accordance with the PRISMA guidelines, a comprehensive search was conducted in April 2021. The databases used are the following: EMBASE, Ovid MEDLINE(R) Epub Ahead of Print, In-Process and Other Non-Indexed Citations, Ovid MEDLINE(R) Daily, Ovid Cochrane Database of Systematic Reviews, and Ovid Cochrane Central Register of Controlled Trials. A manual search from references of other articles and manuscripts from the gray literature was also performed.

\section{Study selection}

The following steps were performed: (1) identification of studies through databases and other methods, (2) removal of duplicates, (3) screening of titles and abstracts and selection of the ones relevant to the research question, (4) full-text article review to assess inclusion eligibility, and (5) review of the selected articles. Two independent investigators (VV, JV) blinded to each other performed the mentioned steps. Disagreements on step (1), (2), and (4) were resolved by a third reviewer (DL) who moderated a discussion for a final determination between the three reviewers.

\section{Data extraction}

The included studies were comprehensively assessed. A data extraction spreadsheet was developed between the co-authors. All data were extracted and entered into a spreadsheet by VV and JV. We included information regarding authors, year of publication, study design, and surgical specialty. Disagreements were resolved by discussion between the two review authors and a third author (DL).

Outcomes included changes in surgical education, quality of social media content, and satisfaction of the population. The actual strategy listing all search terms and how they are combined is available in the "Appendix".

\section{Quality assessment}

Quality assessment of all included studies was evaluated using the JBI (Joanna Briggs Institute) critical appraisal tools $[8,9]$. The descriptive cross-sectional studies were assessed by the JBI critical appraisal checklist for studies reporting prevalence data, an instrument with a 9-item questionnaire related to sampling, data analysis, methodology, statistical analysis, and response rate; while the observational cross-sectional studies were assessed with JBI critical appraisal checklist for analytical cross-sectional studies an 8 -item that evaluated cofounding at the same time as the previously mentioned items. The cohort studies were evaluated with a 12-item quality appraisal that assesses the length of follow-up and the aforementioned items.

\section{Results}

The systematic literature search found 844 articles, and 15 additional records were identified through citation searching. 222 Articles from the database search were found to be duplicates, and therefore, they were excluded from the analysis. The titles and abstracts from the remaining 622 articles were assessed. After careful evaluation, 589 articles were determined to be unrelated to our study and subsequently excluded. The full text of the remaining 33 articles and the 15 articles found through other sources was thoroughly assessed. Letter to the editor, general reviews, surgical specialties other than general surgery, and articles not related to social media were excluded. A total of 24 articles were ultimately included for this review (Fig. 1). The topics covered on the selected articles are mainly assessment of laparoscopic surgeries videos available in YouTube $(n=10$; $42 \%$ ), surveys measuring how often social media is used by surgeons, surgical trainees, and medical students $(n=4$; $17 \%)$, Twitter as tool for surgical education $(n=4 ; 17 \%)$, assessment of private surgical groups on Facebook $(n=3$; $13 \%)$, and tele-mentoring ( $n=3 ; 13 \%$, Table 1$)$.

The design of all studies was determined (Table 1) resulting in $15(n=63 \%)$ analytical observational cross-sectional studies, $7(n=29 \%)$ descriptive cross-sectional studies, and 2 $(n=8 \%)$ analytical observational prospective cohort studies.

After utilizing the JBI quality assessment tool, the analytical observational cross-sectional studies ranged between 7 and 8 positive answers out of 8 questions 
Identification of studies via database

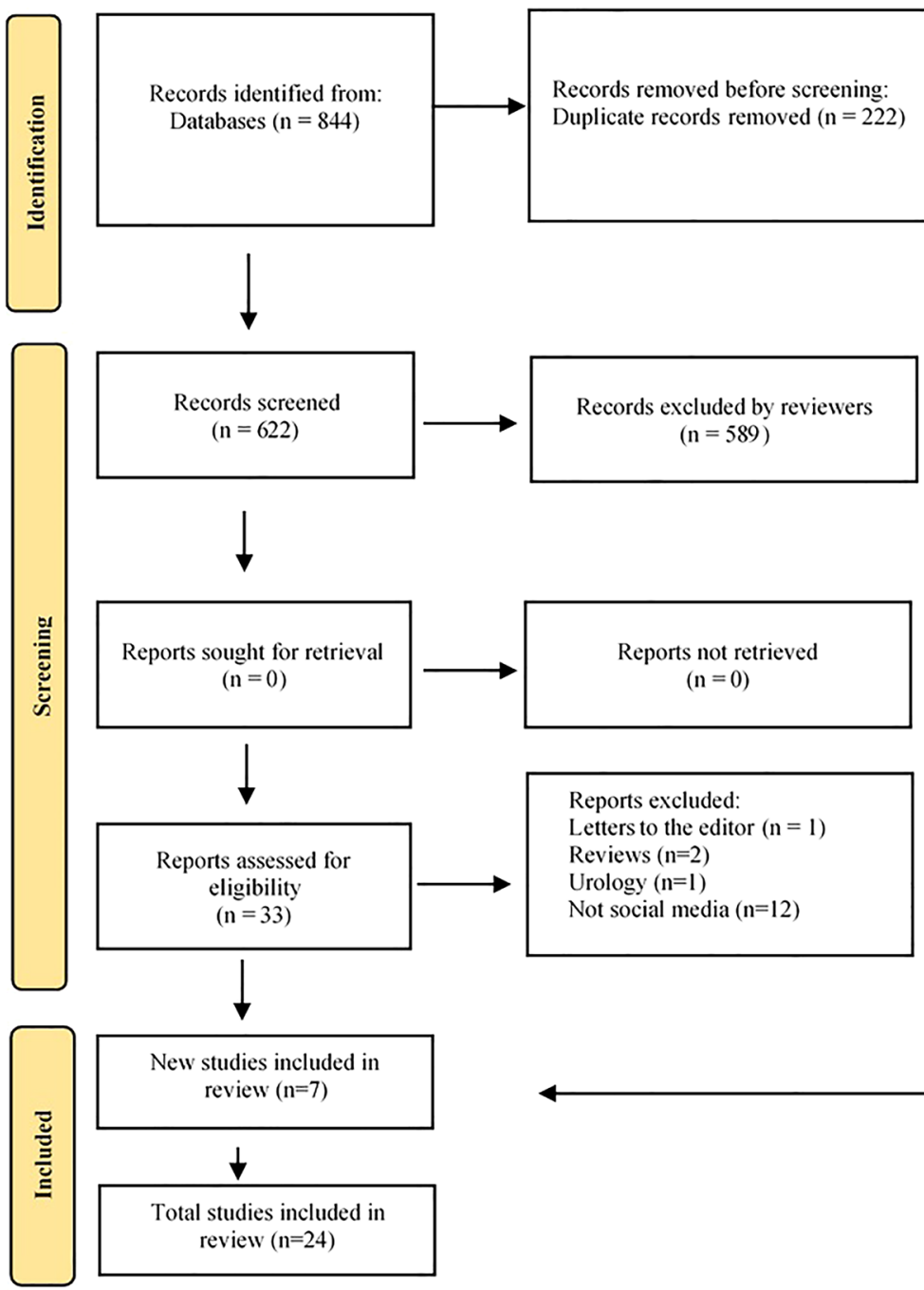

Identification of studies via other methods

Records identified from: Citation searching $(n=15)$
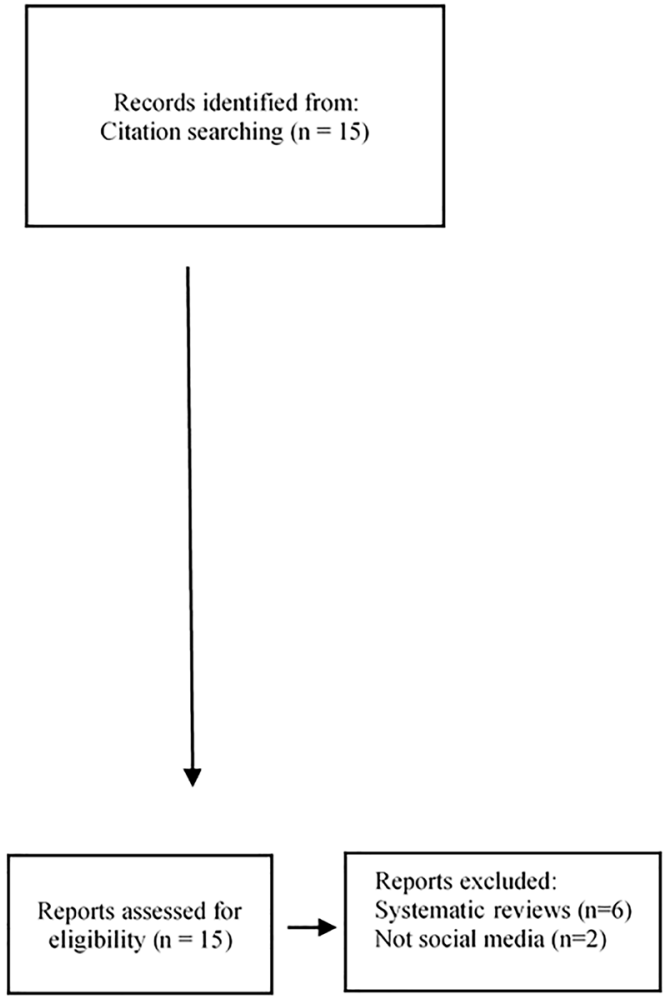

Fig. 1 PRISMA flow diagram [7] for the selection of studies. Includes searches of databases, registers, and other sources

(Table 2), the descriptive cross-sectional studies ranged between 6 and 9 positive answers out of 9 questions (Table 3), and after applying the 11-item questionnaire, the cohort studies resulted in 9 positive answers (Table 4).

Among social media treated on each study, 14 studies ( $n=58 \%$ ) investigated YouTube as video-based surgical education tool and how often is used by medical students, surgical trainees, and surgeons; other articles investigated the importance of Twitter $(n=5 ; 21 \%)$ and Facebook $(n=6 ; 25 \%)$ as source of education, and an article $(n=1 ; 4 \%)$ assessed Whats App as tool for tele-mentoring (Table 5).

\section{Discussion}

A total of 24 studies met our inclusion criteria and were selected for this systematic review. The main topics discussed within the data selected are the usefulness of social media such as YouTube, Facebook, and Twitter in surgical education as well as the content's reliability published on mentioned platforms. Additionally, the COVID-19 pandemic has impacted surgical training programs forcing mentors to opt for other forms of teaching such as 
Table 1 Characteristics of included studies

\begin{tabular}{|c|c|c|c|c|c|}
\hline Author & PY & Surgery & Topic & Participants & Study design \\
\hline Doulias et al. [10] & 2020 & General surgery & $\begin{array}{l}\text { Surgical training in the } \\
\text { COVID-19 era }\end{array}$ & $\begin{array}{l}\text { Available online surgical } \\
\text { training }\end{array}$ & Descriptive: Cross-sectional \\
\hline de'Angelis et al. [11] & 2019 & Laparoscopic surgery & $\begin{array}{l}\text { Educational value of lapa- } \\
\text { roscopic appendectomy } \\
\text { videos on YouTube }\end{array}$ & $\begin{array}{l}\text { Laparoscopic appendec- } \\
\text { tomy YouTube videos }\end{array}$ & $\begin{array}{l}\text { Observational: Cross- } \\
\text { sectional }\end{array}$ \\
\hline Gonzalez et al. [12] & 2012 & Laparoscopic surgery & $\begin{array}{l}\text { Consumer-based technol- } \\
\text { ogy for distribution of } \\
\text { surgical videos for objec- } \\
\text { tive evaluation }\end{array}$ & Surgical residents & Descriptive: Cross-sectional \\
\hline Reitano et al. [13] & 2020 & Laparoscopic surgery & $\begin{array}{l}\text { Educational value of } \\
\text { surgical videos on } \\
\text { transabdominal pre- } \\
\text { peritoneal hernia repair } \\
\text { on YouTube }\end{array}$ & $\begin{array}{l}\text { Laparoscopic TAPP* } \\
\text { YouTube videos }\end{array}$ & $\begin{array}{l}\text { Observational: Cross- } \\
\text { sectional }\end{array}$ \\
\hline Elson et al. [14] & 2021 & General surgery & $\begin{array}{l}\text { Characteristics of general } \\
\text { surgery social media } \\
\text { influencers on Twitter }\end{array}$ & $\begin{array}{l}\text { Surgical residents, general } \\
\text { surgery attendings, and } \\
\text { nonsurgical residents }\end{array}$ & Descriptive: Cross-sectional \\
\hline Chapman et al. [15] & 2021 & Laparoscopic surgery & $\begin{array}{l}\text { Evaluation of laparoscopic } \\
\text { sleeve gastrectomy video } \\
\text { on YouTube using the } \\
\text { LAP-VEGaS guidelines }\end{array}$ & $\begin{array}{l}\text { Laparoscopic sleeve } \\
\text { gastrectomy YouTube } \\
\text { videos }\end{array}$ & $\begin{array}{l}\text { Observational: Cross- } \\
\text { sectional }\end{array}$ \\
\hline Trujillo et al. [16] & 2021 & Laparoscopic surgery & $\begin{array}{l}\text { Telementoring of in-home } \\
\text { real-time laparoscopy } \\
\text { using WhatsApp mes- } \\
\text { senger }\end{array}$ & Surgical residents & Observational: Cohort \\
\hline Zhang et al. [17] & 2020 & Laparoscopic surgery & $\begin{array}{l}\text { Quality, utility and reli- } \\
\text { ability of laparoscopic } \\
\text { gastrectomy videos } \\
\text { for gastric cancer on } \\
\text { YouTube }\end{array}$ & $\begin{array}{l}\text { Laparoscopic gastrectomy } \\
\text { YouTube videos }\end{array}$ & $\begin{array}{l}\text { Observational: Cross- } \\
\text { sectional }\end{array}$ \\
\hline Kanlioz et al. [18] & 2020 & Laparoscopic surgery & $\begin{array}{l}\text { Reliability and educational } \\
\text { features of YouTube } \\
\text { videos about hernia } \\
\text { operations using laparo- } \\
\text { scopic TEP }\end{array}$ & $\begin{array}{l}\text { Laparoscopic TEP* You- } \\
\text { Tube videos }\end{array}$ & $\begin{array}{l}\text { Observational: Cross- } \\
\text { sectional }\end{array}$ \\
\hline Karic et al. [19] & 2020 & General surgery & $\begin{array}{l}\text { Evaluation of surgical edu- } \\
\text { cational videos available } \\
\text { for third year medical } \\
\text { students }\end{array}$ & $\begin{array}{l}\text { Laparoscopic appendec- } \\
\text { tomy and cholecystec- } \\
\text { tomy YouTube videos }\end{array}$ & $\begin{array}{l}\text { Observational: Cross- } \\
\text { sectional }\end{array}$ \\
\hline Toolabi et al. [20] & 2019 & Laparoscopic surgery & $\begin{array}{l}\text { Reliability and educational } \\
\text { value of laparoscopic } \\
\text { sleeve gastrectomy sur- } \\
\text { gery videos on YouTube }\end{array}$ & $\begin{array}{l}\text { Laparoscopic sleeve } \\
\text { gastrectomy YouTube } \\
\text { videos }\end{array}$ & $\begin{array}{l}\text { Observational: Cross- } \\
\text { sectional }\end{array}$ \\
\hline Jackson et al. [21] & 2018 & Foregut surgery & $\begin{array}{l}\text { SAGES foregut surgery } \\
\text { masters programs }\end{array}$ & $\begin{array}{l}\text { SAGES Facebook Group's } \\
\text { Members }\end{array}$ & $\begin{array}{l}\text { Observational: Cross- } \\
\text { sectional }\end{array}$ \\
\hline Rodriguez et al. [22] & 2018 & Laparoscopic surgery & $\begin{array}{l}\text { Quality of the top ten } \\
\text { listed laparoscopy chol- } \\
\text { ecystectomy videos on } \\
\text { YouTube }\end{array}$ & $\begin{array}{l}\text { Laparoscopic cholecystec- } \\
\text { tomy YouTube videos }\end{array}$ & $\begin{array}{l}\text { Observational: Cross- } \\
\text { sectional }\end{array}$ \\
\hline Myers et al. [23] & 2018 & Robotic surgery & $\begin{array}{l}\text { Social media as a platform } \\
\text { for surgical learning }\end{array}$ & $\begin{array}{l}\text { Robotic Surgery Collabo- } \\
\text { ration Facebook Group's } \\
\text { Member }\end{array}$ & $\begin{array}{l}\text { Observational: Cross- } \\
\text { sectional }\end{array}$ \\
\hline Deal et al. [24] & 2017 & Laparoscopic surgery & $\begin{array}{l}\text { Quality and safety of } \\
\text { frequently used laparo- } \\
\text { scopic cholecystectomy } \\
\text { videos }\end{array}$ & $\begin{array}{l}\text { Laparoscopic cholecystec- } \\
\text { tomy YouTube videos }\end{array}$ & $\begin{array}{l}\text { Observational: Cross- } \\
\text { sectional }\end{array}$ \\
\hline
\end{tabular}


Table 1 (continued)

\begin{tabular}{|c|c|c|c|c|c|}
\hline Author & PY & Surgery & Topic & Participants & Study design \\
\hline Lima et al. [25] & 2019 & $\begin{array}{l}\text { Minimally invasive } \\
\text { surgery }\end{array}$ & $\begin{array}{l}\text { The influence of social } \\
\text { media in minimally inva- } \\
\text { sive surgery education }\end{array}$ & $\begin{array}{l}\text { International Hernia Col- } \\
\text { laboration, Mini Friends, } \\
\text { and Robotic Surgery } \\
\text { Collaboration Facebook } \\
\text { Group's Members }\end{array}$ & Descriptive: Cross-sectional \\
\hline Frongia et al. [26] & 2016 & Laparoscopic surgery & $\begin{array}{l}\text { YouTube as a potential } \\
\text { training resource for } \\
\text { laparoscopic fundoplica- } \\
\text { tion }\end{array}$ & $\begin{array}{l}\text { Laparoscopic fundoplica- } \\
\text { tion YouTube videos }\end{array}$ & $\begin{array}{l}\text { Observational: Cross- } \\
\text { sectional }\end{array}$ \\
\hline Lima et al. [27] & 2020 & General surgery & $\begin{array}{l}\text { Social media use for } \\
\text { surgical education during } \\
\text { COVID-19 }\end{array}$ & $\begin{array}{l}\text { Medical students, surgical } \\
\text { residents/fellows, and } \\
\text { practicing surgeons }\end{array}$ & Descriptive: Cross-sectional \\
\hline Rapp et al. [28] & 2016 & General surgery & $\begin{array}{l}\text { Educational video sources } \\
\text { for surgical preparation }\end{array}$ & $\begin{array}{l}\text { Medical students, general } \\
\text { surgery residents, and } \\
\text { faculty surgeons }\end{array}$ & Descriptive: Cross-sectional \\
\hline Buckarma et al. [29] & 2016 & General surgery & $\begin{array}{l}\text { Influence of social media } \\
\text { on the dissemination } \\
\text { of a traditional surgical } \\
\text { research article }\end{array}$ & Journal's website views & Observational: Cohort \\
\hline Mota et al. [30] & 2017 & General surgery & $\begin{array}{l}\text { Video-based surgical } \\
\text { learning }\end{array}$ & $\begin{array}{l}\text { Surgical residents and } \\
\text { surgical specialists }\end{array}$ & Descriptive: Cross-sectional \\
\hline Nikolian et al. [31] & 2018 & General surgery & $\begin{array}{l}\text { Educational content and } \\
\text { the use of Twitter by US } \\
\text { departments of surgery }\end{array}$ & $\begin{array}{l}\text { Accredited general surgery } \\
\text { training programs' Twit- } \\
\text { ter account }\end{array}$ & $\begin{array}{l}\text { Observational: Cross- } \\
\text { sectional }\end{array}$ \\
\hline Gallo et al. [32] & 2019 & General surgery & $\begin{array}{l}\text { Results of a recent tweet } \\
\text { chat about surgical } \\
\text { training }\end{array}$ & $\begin{array}{l}\text { Followers and members of } \\
\text { \#SoMe4Surgery Twitter } \\
\text { community }\end{array}$ & $\begin{array}{l}\text { Observational: Cross- } \\
\text { sectional }\end{array}$ \\
\hline Bernardi et al. [33] & 2020 & General surgery & $\begin{array}{l}\text { A review of the Interna- } \\
\text { tional Hernia Collabora- } \\
\text { tion Facebook Group }\end{array}$ & $\begin{array}{l}\text { International Hernia } \\
\text { Collaboration Facebook } \\
\text { Group's Members }\end{array}$ & $\begin{array}{l}\text { Observational: Cross- } \\
\text { sectional }\end{array}$ \\
\hline
\end{tabular}

$P Y$ publication year, TAPP transabdominal pre-peritoneal hernia repair, $T E P$ totally extraperitoneal

e-learning using application as WhatsApp to conduct remote trainings which demonstrated to be successful [16].

\section{YouTube}

The advent of minimally invasive surgery has turned videobased surgical learning more accessible. Using multimedia as a complement for surgical training has been demonstrated to be effective since multimedia allows the conversion of cognitive input into long-term memory, indicative of learning [30,34]. The high definition of the videos that minimally invasive surgery offers, and the easy accessibility to social media, makes this form of learning widely available. In fact, YouTube is the multimedia platform most frequently used by medical students, surgical trainees, and practicing surgeons to prepare for surgical cases $[15,24,27,28]$. However, most of its content is not peer-reviewed, making this source of information not reliable when looking for educational surgical videos.

YouTube not-peer-review content has brought the attention of many scientists making this topic a substantial target for investigation $[13,15,17,18,20,21,23,26,34]$. Researchers had decided to evaluate the quality and reliability of minimally invasive surgery videos published on YouTube by classifying the data based on surgical approach and technique and then assessing it with different guidelines. Within the studies chosen in this systematic review, the surgical procedures selected were laparoscopic cholecystectomy [18, 21, 23], laparoscopic total extraperitoneal (TEP) hernia repair [34], transabdominal pre-peritoneal hernia repair (TAPP) [13], laparoscopic appendectomy [18, 20], laparoscopic sleeve gastrectomy [15, 20], laparoscopic gastrectomy for gastric cancer [17], and laparoscopic fundoplication [26]. Furthermore, investigators used different methods and/or guidelines to assess the content and quality of the selected videos. Most common methods and guidelines used were the laparoscopic surgery video educational guidelines (LAP-VEGaS) [11,13, 15] (used to report educational videos in laparoscopic surgery) [35], the global operative assessment of laparoscopic skills (GOALS) [11, 22, 24], the global operative assessment of laparoscopic skills-groin hernia (GOALS-GH) [13], the critical view of safety (CVS) 
Table 2 JBI critical appraisal checklist for analytical crosssectional studies [9]
Table 3 JBI critical appraisal checklist for studies reporting prevalence data [8]

\begin{tabular}{lllllllll}
\hline Author & Item 1 & Item 2 & Item 3 & Item 4 & Item 5 & Item 6 & Item 7 & Item 8 \\
\hline de Angelis et al. [11] & Yes & Yes & Yes & Yes & Yes & No & Yes & Yes \\
Reitano et al. [13] & Yes & Yes & Yes & Yes & Yes & No & Yes & Yes \\
Chapman et al. [15] & Yes & Yes & Yes & Yes & Yes & No & Yes & Yes \\
Zhang et al. [17] & Yes & Yes & Yes & Yes & Yes & No & Yes & Yes \\
Kanlioz et al. [18] & Yes & Yes & Yes & Yes & Yes & No & Yes & Yes \\
Karic et al. [19] & Yes & Yes & Yes & Yes & Yes & Yes & Yes & Yes \\
Toolabi et al. [20] & Yes & Yes & Yes & Yes & Yes & Yes & Yes & Yes \\
Jackson et al. [21] & Yes & Yes & Yes & Yes & Yes & Yes & Yes & Yes \\
Rodriguez et al. [22] & Yes & Yes & Yes & Yes & Yes & No & Yes & Yes \\
Myers et al. [23] & Yes & Yes & Yes & Yes & Yes & No & Yes & Yes \\
Deal et al. [24] & Yes & Yes & Yes & Yes & Yes & No & Yes & Yes \\
Frongia et al. [26] & Yes & Yes & Yes & Yes & Yes & Yes & Yes & Yes \\
Nikolian et al. [31] & Yes & Yes & Yes & Yes & Yes & Yes & Yes & Yes \\
Gallo et al. [32] & Yes & Yes & Yes & Yes & Yes & No & Yes & Yes \\
Bernardi et al. [33] & Yes & Yes & Yes & Yes & Yes & No & Yes & Yes \\
\hline
\end{tabular}

JBI Joanna Briggs Institute, Item 1 Were the criteria for inclusion in the sample clearly defined?, Item 2 Were the study subjects and the setting described in detail?, Item 3 Was the exposure measured in a valid and reliable way?, Item 4 Were objective, standard criteria used for measurement of the condition?, Item 5 Were confounding factors identified?, Item 6 Were strategies to deal with confounding factors stated?, Item 7 Were the outcomes measured in a valid and reliable way?, Item 8 Was appropriate statistical analysis used?

\begin{tabular}{llllllllll}
\hline Author & Item 1 & Item 2 & Item 3 & Item 4 & Item 5 & Item 6 & Item 7 & Item 8 & Item 9 \\
\hline Doulias et al. [10] & Yes & Yes & Yes & Yes & Yes & Yes & Yes & No & Not applicable \\
Gonzalez et al. [12] & Yes & Yes & Yes & Yes & No & Yes & Yes & No & Not applicable \\
Elson et al. [14] & Yes & Yes & Yes & Yes & Yes & Yes & Yes & Yes & Yes \\
Lima et al. [25] & Yes & Yes & Yes & Yes & Yes & Yes & Yes & Yes & Yes \\
Lima et al. [27] & Yes & Yes & Yes & Yes & Yes & Yes & Yes & Yes & Yes \\
Rapp et al. [28] & Yes & Yes & Yes & Yes & Yes & Yes & Yes & Yes & Yes \\
Mota et al. [30] & Yes & Yes & Yes & Yes & Yes & Yes & Yes & Yes & Yes
\end{tabular}

JBI Joanna Briggs Institute, Item 1 Was the sample frame appropriate to address the target population?, Item 2 Were study participants sampled in an appropriate way?, Item 3 Was the sample size adequate?, Item 4 Were the study subjects and the setting described in detail?, Item 5 Was the data analysis conducted with sufficient coverage of the identified sample?, Item 6 Were valid methods used for the identification of the condition?, Item 7 Was the condition measured in a standard, reliable way for all participants?, Item 8 Was there appropriate statistical analysis?, Item 9 Was the response rate adequate, and if not, was the low response rate managed appropriately?

Table 4 JBI critical appraisal checklist for prevalence cohort studies [9]

\begin{tabular}{llllllllllll}
\hline Author & Item 1 & Item 2 & Item 3 & Item 4 & Item 5 & Item 6 & Item 7 & Item 8 & Item 9 & Item 10 & Item 11 \\
\hline Trujillo et al. [16] & Yes & Yes & Yes & Yes & No & Yes & Yes & Yes & Yes & Not applicable & Yes \\
Buckarma et al. [29] & Yes & Yes & Yes & Yes & No & Yes & Yes & Yes & Yes & Not applicable & Yes \\
\hline
\end{tabular}

JBI Joanna Briggs Institute, Item 1 Were the two groups similar and recruited from the same population?, Item 2 Were the exposures measured similarly to assign people to both exposed and unexposed groups?, Item 3 Was the exposure measured in a valid and reliable way?, Item 4 Were confounding factors identified?, Item 5 Were strategies to deal with confounding factors stated?, Item 6 Were the groups/participants free of the outcome at the start of the study (or at the moment of exposure)?, Item 7 Were the outcomes measured in a valid and reliable way?, Item 8 Was the follow-up time reported and sufficient to be long enough for outcomes to occur?, Item 9 Was follow-up complete, and if not, were the reasons to loss to follow up described and explored?, Item 10 Were strategies to address incomplete follow-up utilized?, Item 11 Was appropriate statistical analysis used? 
Table 5 Social media platforms assessed on each study

\begin{tabular}{|c|c|c|c|c|}
\hline Author & YouTube & Facebook & Twitter & WhatsApp \\
\hline Doulias et al. [10] & $X$ & $\mathrm{X}$ & $\mathrm{X}$ & \\
\hline de'Angelis et al. [11] & $\mathrm{X}$ & & & \\
\hline Gonzalez et al. [12] & $\mathrm{X}$ & & & \\
\hline Reitano et al. [13] & $\mathrm{X}$ & & & \\
\hline Elson et al. [14] & & & $X$ & \\
\hline Chapman et al. [15] & $\mathrm{X}$ & & & \\
\hline Trujillo et al. [16] & & & & $X$ \\
\hline Zhang et al. [17] & $X$ & & & \\
\hline Kanlioz et al. [18] & $\mathrm{X}$ & & & \\
\hline Karic et al. [19] & $X$ & & & \\
\hline Toolabi et al. [20] & $\mathrm{X}$ & & & \\
\hline Jackson et al. [21] & & $\mathrm{X}$ & & \\
\hline Rodriguez et al. [22] & $X$ & & & \\
\hline Myers et al. [23] & & $X$ & & \\
\hline Deal et al. [24] & $X$ & & & \\
\hline Lima et al. [25] & & $\mathrm{X}$ & & \\
\hline Frongia et al. [26] & $\mathrm{X}$ & & & \\
\hline Lima et al. [27] & & $X$ & & \\
\hline Rapp et al. [28] & $X$ & & & \\
\hline Buckarma et al. [29] & & & $X$ & \\
\hline Mota et al. [30] & $X$ & & & \\
\hline Nikolian et al. [31] & & & $\mathrm{X}$ & \\
\hline Gallo et al. [32] & & & $\mathrm{X}$ & \\
\hline Bernardi et al. [33] & & $\mathrm{X}$ & & \\
\hline
\end{tabular}

score [11, 22, 24] (used to assess laparoscopic cholecystectomy videos), video power index (VPI) [17, 18], the Journal of American Medical Association (JAMA) benchmark criteria [17, 18] (used to assess authorship, attribution, disclosure, and currency) [36], the objective component rating scale (OCRS, used to assess laparoscopic fundoplication) [26], and educational quality rating score (EQRS, used to assess surgical treatment of gastroesophageal reflux disease) [26]. Even though using different methods to assess these YouTube videos, researchers obtained low percentage of the data meeting full criteria $(<1 \%$ [22, 24], 1.6\% [17], $8 \%$ [11, $20], 12.5 \%$ [13]), meaning that this widely available multimedia is not the best source for surgical education. Most videos are lacking crucial information such as the patient's preoperative data, theater time, operation set up, patient's morbidity, and outcomes, which are topics needed to be explained when developing appropriate educational surgical videos [15]. However, Frogia, G., et al. stated that even though the high variance of videos uploaded on YouTube, by evaluating specific criteria, it is possible to find "good-quality" videos (39.4\%) [26]. Regardless of this last statement, authors encourage medical students, surgical trainees, and practicing surgeons to look for peer-review content as well as to follow guidelines when creating educational videos; an example of how to follow guidelines when creating educational videos is the study performed by Gonzalez, R., et al. where laparoscopic cholecystectomy in porcine model videos was recorded, edited, and then uploaded in platforms such as YouTube, iPhones, and others [12].

\section{Facebook}

Facebook is another popular social media used by the surgical community. Private groups have been created serving as an open discussion and collaborative platform for surgeons. These groups offer a variety of content such as live surgery, material from important congresses, specialty courses, surgical quizzes, clinical cases, exam topics, and archived footage from procedures performed by experts [10]. This information widely available for its members contributes to the acquisition and/or reinforcement of knowledge to alllevel experienced surgeons and trainees, potentially representing another surgical teaching platform. In fact, Jackson, $H$., et al. conducted a study analyzing the content the Society of American Gastrointestinal and Endoscopic Surgeons (SAGES) publishes in their page [21]. The content posted on the group mostly involved operative technique (64\% of the posts), patient management (54\% of posts), continuing education (10\% of posts), and networking ( $10 \%$ of posts) [21]. The frequency of use by the members of these groups has been measured to determine how impactful is the information posted on the daily workflow of these professionals. Myers, C., et al. found that members of the Robotic Surgery Collaboration (RSC) Facebook group actively (making comments) and passively (liking posts) interact with this platform more frequently during midweek days, suggesting that surgeons and trainees use this platform as part of their professional development and practice [23]. Lima, D., et al. distributed a survey on the International Hernia Collaboration (IHC), Mini Friend, and RSC Facebook groups and found that $50 \%$ of the participants published complicated cases on these private groups, comment on other surgeons' cases, and incorporated to their practice tips or tricks recommended by experienced surgeons; again, supporting the fact that Facebook is being used for teaching and learning purposes [25].

However, as Facebook is a popular and open-access platform, the risk for unsafe, inaccurate, and not guideline-based information found within these private groups, it is very likely. Bernardi, K., et al. assessed the content published on the IHC Facebook Group and stablished that for discussion of a clinical case to be considered safe and useful, the comments on a post should be evidence-based, guideline-based, or current practice of acceptable care agreed by three expert hernia surgeons and that dangerous or unsafe comments should be corrected [33]. It was found in the IHC Facebook group that most posts' responses were safe (96.6\%) but some 
of them were unhelpful (28.4\%). Not least important, few comments were found to be unsafe $(2.3 \%)$ and just 4 out of 14 comments were corrected. The authors considered IHC a safe and useful platform for surgeons; however, investigators claim for mechanisms to identify and correct unsafe advice as well as to always provide evidence-based management strategies to improve the quality and reliability of information posted and to prevent patients' harm [33].

\section{Twitter}

Twitter is the other preferred SM, in fact, the most popular, used for healthcare communication [14, 32]. Within the surgical community, it represents another open-access platform that allows instant communication and digital discussion between followers, the opportunity of massively share up to date articles, guidelines and current clinical trials, and highquality educational content in real-time [32]. Twitter healthcare accounts go from personals (most famous surgical influencers are described by Elson, N., et al.) [14] to institutional such as surgery training programs and journals. Surgery training programs have created accounts to engage with students, surgeons, and even with other institutions. However, Nikolian, V.C. et al. stated that general surgery programs use their Twitter accounts for promotion more than for educational content, and the dilemma is that the former does not engage followers to interact as much as the later does [31]. In view of this, the authors suggest these accounts to tweet more educational content to fully take advantage that this tool offers as a teaching platform [31]. Additionally, journals and authors have opted to tweet most recent articles since the receptiveness has been demonstrated to be higher as if the article is just promoted on the journal website [29]. Twitter has been used as well by investigators to spread surveys with different topic subjects. Gallo, G., et al. conducted a survey to assess what is considered a "good" surgery program based on residents' opinion. Between the most relevant responses that complement this systematic review was that trainees travel to learn from renowned mentors; Twitter, in contrasts, is a platform that could bring together professionals regardless of the geographic location, allowing these mentors to be more reachable for students [32]. Residents also agreed that digital technology is an important instrument for improving high-quality surgical training [32], opinion that supports the current use that has been given to Twitter, as a learning platform which ultimately gets good results such as improving the quality of care offered to patients.

\section{COVID-19 pandemic}

During the COVID-19 pandemic, social media has served as an educational platform to improve patients' care regardless of the social isolation. Besides SM serving as main medium to spread the newest events related to COVID-19, it has also served as an e-learning platform. Trujillo, $Y$., et al. conducted a cohort study using WhatsApp messenger as a tool to teach laparoscopic techniques in real time [16]. Successful results obtained, supported that remote laparoscopic training in real time with smartphone is effective in terms of acquisition of laparoscopic skills after tele-mentoring. Once again, social media demonstrates to be a potential tool for e-learning. In fact, after COVID-19 pandemic, possible changes on surgical education curriculum have been discussed [10]. One of the changes is including e-learning to complement training, since many residents were exposed less hours on surgical services, required by the surgical program curriculum, due to being redeployed to COVID-19 units. e-Learning could help to replenish those lost hours of surgical learning. Anyhow, including e-learning or not to the surgical curriculum, residents and practicing surgeons are already using SM looking to acquired new and/or to reinforced knowledge [27].

Docimo Jr., et al. have showed an increase in membership and utilization of closed Facebook surgical groups during the pandemic when compared with a pre-pandemic time [38]. Our group has also investigated the increase in the audience of an online platform (HerniaU) for surgical education during the pandemic [39].

\section{Quality assessment}

Among the analytical cross-sectional studies, 4 studies had all positive answers when applying the 8 -item questionnaire, while 11 studies lacked strategies to deal with the cofounding factors. On the other hand, between the descriptive crosssectional studies, 5 studies fulfilled the 9-item questionnaire, while 2 had absence of an appropriate statistical analysis. Furthermore, both cohort studies did not identify the confounding factors, and both completed follow-up, therefore obtaining 9 positive answers out of 11-item questionnaire. Based on the aforementioned, the overall appraisal of the 24 studies resulted adequate for inclusion in this systematic review.

\section{Patient confidentiality and informed consent}

Surgeons and students should be aware not only of the lack of peer-review in what is posted online, but also regarding data privacy and informed consent. The SAGES published a statement in 2019 endorsing the professional use of social media for surgical education [37]. Moreover, an informed consent policy should be used to protect patients, surgeons, and other providers when posting on social media platforms. The biggest challenge for the future is to identify reliable sources on the Internet which should also protect patient confidentiality. 


\section{Limitations}

The limitations of our study include language, specialties other than general surgery, and publication bias. We included only manuscripts published in English, Spanish, and Portuguese, while studies published in other languages may have been inadvertently excluded. Surgical specialties other than general surgery were not included due to investigators' common interest. Despite the broad literature search, we may not have identified all studies pertaining to social media and surgical education. Additionally, our delineated criteria may have also excluded additional studies.

\section{Conclusions}

The use of social media is increasing exponentially. Even though a significant amount of content published is not peer-reviewed, engagement with social media is inevitable and many members of these platform are working toward publishing reliable and useful information. SM cannot be ignored anymore by mentors, trainees, surgical institutions, and journals. Advantages that SM offers should be considered, and content creators and institutions should help collectively to make sure that the content being published is evidence and guideline-based so its use it is taken to the maximum benefit. By working together, SM could transform into an invaluable tool for teaching and learning goals in surgery and any other medical field.

\section{Appendix}

Database: EMBASE 1974 to 11 April 2021

\begin{tabular}{lll}
\hline \# & Searches & Results \\
\hline 1 ('social media'/exp OR (((social NEXT/1 (media OR & 402 \\
& medium)):ti,ab,kw) OR 'twitter messaging':ti,ab,kw & \\
& OR web:ti,ab,kw OR twittter:ti,ab,kw OR \\
& linkedin:ti,ab,kw OR facebook:ti,ab,kw OR \\
& whatsapp:ti,ab,kw) OR 'social network'/exp \\
& OR (((social NEXT/1 network*):ti,ab,kw) OR \\
& networking:ti,ab,kw)) AND (('e-learning'/exp OR \\
& ((((online OR distance OR blended) NEXT/1 (educa- \\
& tion OR learning OR course*)):ti,ab,kw) OR ‘cor- \\
& respondence course*':ti,ab,kw) OR (teach:ti,ab,kw \\
& OR teaching:ti,ab,kw OR trainee:ti,ab,kw OR \\
& training:ti,ab,kw OR education:ti,ab,kw OR \\
& learning:ti,ab,kw)) AND (('laparoscopy'/exp OR \\
& 'robotics'/exp OR 'minimally invasive surgery'/exp) \\
& OR ((laparoscopic OR robot OR robotic OR minimal \\
& OR minimally) NEXT/3 (procedure* OR surg* OR \\
& resect* OR operat*)):ti,ab,kw)) \\
\hline
\end{tabular}

Database(s): Ovid MEDLINE(R) and Epub Ahead of Print, In-Process, In-Data-Review and Other Non-Indexed Citations and Daily 1946 to 9 April 2021

\begin{tabular}{|c|c|c|}
\hline \# & Searches & Results \\
\hline 1 & exp Social Media/ & 9682 \\
\hline 2 & $\begin{array}{l}\text { ((social adj (media or medium)) or "twitter messag- } \\
\text { ing" or web or twitter or youtube or linkedin or } \\
\text { facebook or whatsapp).ti,ab,hw,kw }\end{array}$ & 149,079 \\
\hline 3 & exp Social Networking/ & 4415 \\
\hline 4 & ("social network*" or networking).ti,ab,hw,kw & 28,237 \\
\hline 5 & 1 or 2 or 3 or 4 & 173,185 \\
\hline 6 & exp Education, Distance / & 4795 \\
\hline 7 & $\begin{array}{l}\text { (((online or distance or blended) adj (education } \\
\text { or learning or course*)) or “correspondence } \\
\text { course*”).ti,ab,hw,kw }\end{array}$ & 5914 \\
\hline 8 & $\begin{array}{l}\text { (teach or teaching or trainee or training or education } \\
\text { or learning).ti,ab,hw,kw }\end{array}$ & $1,531,529$ \\
\hline 9 & 6 or 7 or 8 & $1,531,649$ \\
\hline 10 & $\begin{array}{l}\text { exp Laparoscopy/or exp Robotics/or exp Minimally } \\
\text { Invasive Surgical Procedure/ }\end{array}$ & 555,289 \\
\hline 11 & $\begin{array}{l}\text { ((laparoscopic or robot or robotic or minimal or } \\
\text { minimally) adj3 (procedure* or surg* or resect* or } \\
\text { operat*).ti,ab,hw,kw }\end{array}$ & 103,635 \\
\hline 12 & 10 or 11 & 585,903 \\
\hline 13 & 9 and 12 & 30,219 \\
\hline 14 & 5 and 13 & 399 \\
\hline 15 & remove duplicates from 14 & 397 \\
\hline
\end{tabular}

Database(s) EBM Reviews-Cochrane Central Register of Controlled Trials March 2021, EBM Reviews-Cochrane Database of Systematic Reviews 2005 to 8 April 2021

\begin{tabular}{|c|c|c|}
\hline \# & Searches & Results \\
\hline 1 & exp Social Media/ & 173 \\
\hline 2 & $\begin{array}{l}\text { ((social adj (media or } \\
\text { medium)) or "twitter mes- } \\
\text { saging" or web or twitter } \\
\text { or youtube or linkedin or } \\
\text { facebook or whatsapp). } \\
\text { ti,ab,hw,kw }\end{array}$ & 14,275 \\
\hline 3 & exp Social Networking/ & 103 \\
\hline 4 & $\begin{array}{l}\text { ("social network*" or net- } \\
\text { working).ti,ab,hw,kw }\end{array}$ & 1922 \\
\hline 5 & 1 or 2 or 3 or 4 & 16,262 \\
\hline 6 & exp Education, Distance / & 167 \\
\hline 7 & $\begin{array}{l}\text { (((online or distance or } \\
\text { blended) adj (education } \\
\text { or learning or course*)) } \\
\text { or “correspondence } \\
\text { course*”).ti,ab,hw,kw }\end{array}$ & 657 \\
\hline 8 & $\begin{array}{l}\text { (teach or teaching or trainee } \\
\text { or training or education or } \\
\text { learning).ti,ab,hw,kw }\end{array}$ & 177,371 \\
\hline 9 & 6 or 7 or 8 & 177,409 \\
\hline
\end{tabular}




\begin{tabular}{|c|c|c|}
\hline$\#$ & Searches & Results \\
\hline$\overline{10}$ & $\begin{array}{l}\text { exp Laparoscopy/or exp } \\
\text { Robotics/or exp Mini- } \\
\text { mally Invasive Surgical } \\
\text { Procedure/ }\end{array}$ & 28,420 \\
\hline 11 & $\begin{array}{l}\text { ((laparoscopic or robot or } \\
\text { robotic or minimal or } \\
\text { minimally) adj3 (proce- } \\
\text { dure* or surg* or resect* } \\
\text { or operat*)).ti,ab,hw,kw }\end{array}$ & 16,512 \\
\hline 12 & 10 or 11 & 41,647 \\
\hline 13 & 9 and 12 & 3244 \\
\hline 14 & 5 and 13 & 44 \\
\hline 15 & remove duplicates from 14 & 40 \\
\hline
\end{tabular}

Supplementary Information The online version contains supplementary material available at https://doi.org/10.1007/s00464-022-09150-9.

Funding There was no funding for this research project.

Disclosures Dr. Malcher discloses consulting fees from Intuitive, BD and Medtronic, outside the submitted work. Drs. Diego Lima, Valentina Viscarret, Juan Velasco, and Raquel Nogueira C. L. Lima have no conflict of interests.

\section{References}

1. Bennett KG, Berlin NL, MacEachern MP, Buchman SR, Preminger BA, Vercler CJ (2018) The ethical and professional use of social media in surgery: a systematic review of the literature. Plast Reconstr Surg 142(3):388e-398e. https://doi.org/10.1097/ PRS.0000000000004692

2. Azoury SC, Bliss LA, Ward WH, Liepert AE, Leichtle SW (2015) Surgeons and social media: threat to professionalism or an essential part of contemporary surgical practice? Bull Am Coll Surg 100(8):45-51

3. Wilkinson SE, Basto MY, Perovic G, Lawrentschuk N, Murphy DG (2015) The social media revolution is changing the conference experience: analytics and trends from eight international meetings. BJU Int 115(5):839-846. https://doi.org/10.1111/bju.12910

4. Loeb S, Catto J, Kutikov A (2014) Social media offers unprecedented opportunities for vibrant exchange of professional ideas across continents. Eur Urol 66(1):118-119. https://doi.org/10. 1016/j.eururo.2014.02.048

5. Azoury SC, Mazzaferro DM, Piwnica-Worms W, Messa CA 4th, Othman S, Stranix JT, Serletti JM, Kovach SJ, Fosnot J (2020) An update on social media in academic plastic surgery training programs: the rising trend of likes, shares, and retweets. Ann Plast Surg 85(2):100-104. https://doi.org/10.1097/SAP.0000000000 002289

6. Newall N, Smith BG, Burton O, Chari A, Kolias AG, Hutchinson PJ, Alamri A, Uff C, Brainbook (2021) Improving neurosurgery education using social media case-based discussions: a pilot study. World Neurosurg X 11:100103. https://doi.org/10.1016/j.wnsx. 2021.100103
7. Page MJ, McKenzie JE, Bossuyt PM, Boutron I, Hoffman TC, Mulrow CD et al (2021) The PRISMA 2020 statement: an updated guideline for reporting systematic reviews. BMJ 372:n71. https:// doi.org/10.1136/bmj.n71

8. Munn Z, Moola S, Lisy K, Riitano D, Tufanaru C (2015) Methodological guidance for systematic reviews of observational epidemiological studies reporting prevalence and incidence data. Int J Evid Based Healthc 13(3):147-153. https://doi.org/10.1097/XEB. 0000000000000054

9. Moola S, Munn Z, Tufanaru C, Aromataris E, Sears K, Sfetcu R, Currie M, Qureshi R, Mattis P, List K, Mu P (2020) Chapter 7: Systematic reviews of etiology and risk - JBI Manual for Evidence Synthesis - JBI Global Wiki [Internet]. [cited 2021 Oct 20]. Available from: https://jbi-global-wiki.refined.site/space/MANUAL/ $3283910762 /$ Chapter+7\%3A +Systematic+reviews+of+etiol ogy+and+risk. https://doi.org/10.46658/JBIMES-20-08

10. Doulias T, Gallo G, Rubio-Perez I, Breukink SO, Hahnloser D (2020) Doing more with less: surgical training in the COVID-19 era. J Investig Surg. https://doi.org/10.1080/08941939.2020.18242 50

11. de Angelis N, Gavriilidis P, Martínez-Pérez A, Genova P, Notarnicola M, Reitano E, Petrucciani N, Abdalla S, Memeo R, Brunetti F, Carra MC, Di Saverio S, Celentano V (2019) Educational value of surgical videos on YouTube: quality assessment of laparoscopic appendectomy videos by senior surgeons vs. novice trainees. World J Emerg Surg 14(1):22. https://doi.org/10.1186/ s13017-019-0241-6

12. Gonzalez R, Martinez JM, Lo Menzo E, Iglesias AR, Ro CY, Madan AK (2012) Consumer-based technology for distribution of surgical videos for objective evaluation. Surg Endosc 26(8):21792182. https://doi.org/10.1007/s00464-011-2018-1

13. Reitano E, Cavalli M, de Angelis N, Loriau J, Campanelli G (2020) Educational value of surgical videos on transabdominal pre-peritoneal hernia repair (TAPP) on YouTube. Hernia 25(3):741-753. https://doi.org/10.1007/s10029-020-02171-0

14. Elson NC, Le DT, Johnson MD, Reyna C, Shaughnessy EA, Goodman MD, Lewis JD (2021) Characteristics of general surgery social media influencers on Twitter. Am Surg 87(3):492-498. https://doi.org/10.1177/0003134820951427

15. Chapman D, Weaver A, Sheikh L, MacCormick AD, Poole G (2021) Evaluation of online videos of laparoscopic sleeve gastrectomy using the LAP-VEGaS guidelines. Obes Surg 31(1):111116. https://doi.org/10.1007/s11695-020-04876-8

16. Trujillo Y, Trejo MD, Campos S (2021) Telementoring of in-home real-time laparoscopy using WhatsApp messenger: an innovative teaching tool during the COVID-19 pandemic. A cohort study. Ann Med Surg (Lond) 62:481-484. https://doi.org/10.1016/j. amsu.2021.01.085

17. Zhang S, Fukunaga T, Oka S, Orita H, Kaji S, Yube Y, Yamauchi S, Kohira Y, Egawa H (2020) Concerns of quality, utility, and reliability of laparoscopic gastrectomy for gastric cancer in public video sharing platform. Ann Transl Med 8(5):196. https://doi.org/ 10.21037/atm.2020.01.78

18. Kanlioz M, Ekici U (2020) Reliability and educational features of YouTube videos about hernia operations performed using laparoscopic TEP method. Surg Laparosc Endosc Percutan Tech 30(1):74-78. https://doi.org/10.1097/SLE.0000000000000748

19. Karic B, Moino V, Nolin A, Andrews A, Brisson P (2020) Evaluation of surgical educational videos available for third year medical students. Med Educ Online 25(1):1714197. https://doi.org/10. 1080/10872981.2020.1714197

20. Toolabi K, Parsaei R, Elyasinia F, Zamanian A (2019) Reliability and educational value of laparoscopic sleeve gastrectomy surgery videos on YouTube. Obes Surg 29(9):2806-2813. https://doi.org/ 10.1007/s11695-019-03907-3 
21. Jackson HT, Young MT, Rodriguez HA, Wright AS (2018) SAGES Foregut Surgery Masters Program: a surgeon's social media resource for collaboration, education, and professional development. Surg Endosc 32(6):2800-2807. https://doi.org/10. 1007/s00464-017-5983-1

22. Rodriguez HA, Young MT, Jackson HT, Oelschlager BK, Wright AS (2018) Viewer discretion advised: is YouTube a friend or foe in surgical education? Surg Endosc 32(4):1724-1728. https://doi. org/10.1007/s00464-017-5853-x

23. Myers CG, Kudsi OY, Ghaferi AA (2018) Social media as a platform for surgical learning: use and engagement patterns among robotic surgeons. Ann Surg 267(2):233-235. https://doi.org/10. 1097/SLA.0000000000002479

24. Deal SB, Alseidi AA (2017) Concerns of quality and safety in public domain surgical education videos: an assessment of the critical view of safety in frequently used laparoscopic cholecystectomy videos. J Am Coll Surg 225(6):725-730. https://doi.org/ 10.1016/j.jamcollsurg.2017.08.016

25. Lima DL, Nogueira R, Lopes G, Malcher F (2019) The influence of social media in minimally invasive surgery education: how surgeons exchange experience and knowledge in these platforms. J Minimal Access Surg 15(3):275-276. https://doi.org/10.4103/ jmas.JMAS_270_18

26. Frongia G, Mehrabi A, Fonouni H, Rennert H, Golriz M, Günther $\mathrm{P}$ (2016) YouTube as a potential training resource for laparoscopic fundoplication. J Surg Educ 73(6): 1066-1071. https://doi.org/10. 1016/j.jsurg.2016.04.025

27. Lima D, Nogueira Cordeiro Laurentino Lima R, Benevenuto D, Soares Raymundo T, Shadduck PP, Melo Bianchi J, Malcher F (2020) Survey of social media use for surgical education during COVID-19. JSLS 24(4):e2020.00072. https://doi.org/10.4293/ JSLS.2020.00072

28. Rapp AK, Healy MG, Charlton ME, Keith JN, Rosenbaum ME, Kapadia MR (2016) YouTube is the most frequently used educational video source for surgical preparation. J Surg Educ 73(6):1072-1076. https://doi.org/10.1016/j.jsurg.2016.04.024

29. Buckarma EH, Thiels CA, Gas BL, Cabrera D, Bingener-Casey J, Farley DR (2017) Influence of social media on the dissemination of a traditional surgical research article. J Surg Educ 74(1):79-83. https://doi.org/10.1016/j.jsurg.2016.06.019

30. Mota P, Carvalho N, Carvalho-Dias E, João Costa M, CorreiaPinto J, Lima E (2018) Video-based surgical learning: improving trainee education and preparation for surgery. J Surg Educ 75(3):828-835. https://doi.org/10.1016/j.jsurg.2017.09.027

31. Nikolian VC, Barrett M, Valbuena VS, Ibrahim AM, Eidy H, Ghandour MH, Ghaferi AA (2018) Educational content and the use of social media at US departments of surgery. Surgery 163(2):467-471. https://doi.org/10.1016/j.surg.2017.10.039
32. Gallo G, Sturiale A, De Simone V, Mayol J (2021) Epistemic networks on Twitter: a new way to learn. J Investig Surg 34(5):536544. https://doi.org/10.1080/08941939.2019.1656787

33. Bernardi K, Milton AN, Hope W, Roth JS, Shah SK, Shah P, Lyons NB, Martin AC, Holihan JL, Cherla DV, Ko TC, Hughes TG, Liang MK (2020) Are online surgical discussion boards a safe and useful venue for surgeons to ask for advice? A review of the International Hernia Collaboration Facebook Group. Surg Endosc 34(3):1285-1289. https://doi.org/10.1007/s00464-019-06895-8

34. Mayer RE (2008) Applying the science of learning: evidencebased principles for the design of multimedia instruction. Am Psychol 63(8):760-769. https://doi.org/10.1037/0003-066X.63.8. 760

35. Celentano V, Smart N, McGrath J, Cahill RA, Spinelli A, Obermair A, Hasegawa H, Lal P, Almoudaris AM, Hitchins CR, Pellino G, Browning MG, Ishida T, Luvisetto F, Cingiloglu P, Gash K, Harries R, Harji D, Di Candido F, Cassinotti E, McDermott F, Berry JE, Battersby NJ, Platt E, Campaign NJ, Keeler BD, Boni L, Gupna S, Griffith JP, Acheson AG, Cecil TD, Coleman MG (2018) LAP-VEGaS practice guidelines for reporting of educational videos in laparoscopic surgery: a joint trainers and trainees consensus statement. Ann Surg 268(6):920-926. https://doi.org/ 10.1097/SLA.0000000000002725

36. Bruce-Brand RA, Baker JF, Byrne DP, Hogan NA, McCarthy T (2013) Assessment of the quality and content of information on anterior cruciate ligament reconstruction on the internet. Arthroscopy 29(6):1095-1100. https://doi.org/10.1016/j.arthro.2013.02. 007

37. Bittner JG, Logghe HJ, Kane ED, Goldberg RF, Alseidi A, Aggarwal R et al (2019) A Society of Gastrointestinal and Endoscopic Surgeons (SAGES) statement on closed social media (Facebook $\left.{ }^{\circledR}\right)$ groups for clinical education and consultation: issues of informed consent, patient privacy, and surgeon protection. Surg Endosc 33(1):1-7

38. Docimo S, Jacob B, Seras K, Ghanem O (2021) Closed Facebook groups and COVID-19: an evaluation of utilization prior to and during the pandemic. Surg Endosc 35(9):4986-4990

39. Malcher F, Lima DL, Cavazzola LT, Cl Lima RN, Davila EP, Morales-Conde S (2021) Surgical education during pandemic times: how the virtual world can help us in real life? The Hernia U experience. Cir Esp (Engl Ed) 99(4):315-316

Publisher's Note Springer Nature remains neutral with regard to jurisdictional claims in published maps and institutional affiliations. 